\title{
Aspirin Therapy for Primary Prevention: The Case for Continuing Prescribing to Patients at High Cardiovascular Risk-A Review
}

\author{
Raffaele De Caterina ${ }^{1}$ Alberto Aimo ${ }^{1}$ Paul M. Ridker ${ }^{2}$ \\ ${ }^{1}$ Cardiovascular Division, Pisa University Hospital, University of Pisa, \\ Pisa, Italy \\ ${ }^{2}$ Cardiovascular Division, Brigham and Women's Hospital, Harvard \\ Medical School, Boston, Massachusetts, United States \\ Address for correspondence Raffaele De Caterina, MD, PhD, \\ Cardiovascular Division, Department of Cardiology, Pisa University \\ Hospital, University of Pisa, Via Paradisa 2, Pisa 56124, Italy \\ (e-mail: raffaele.decaterina@unipi.it).
}

Thromb Haemost 2020;120:199-206.

\begin{abstract}
Keywords

- aspirin

- primary cardiovascular prevention

- bleeding

- major acute cardiovascular events

- MACE

- benefit-risk balance

Current evidence supports the use of low-dose aspirin for secondary cardiovascular prevention. By contrast, the benefit-to-risk ratio of aspirin use in primary prevention is debated: three contemporary randomized control trials have been conflicting, and meta-analyses have concluded for an unclear clinical benefit, based on the consideration that the reduction in thromboembolic events is counterbalanced by increased bleeding. The primary prevention setting is, however, a heterogeneous mix of subjects at highly variable cardiovascular risk. One possible explanation for the uncertainty of data interpretation is the progressive reduction in risk of major adverse cardiovascular events (MACEs) in primary prevention that has accompanied global education programs, leading patients to smoke less, exercise more, and increasingly take lipidlowering therapies. Based on a meta-regression of the benefits and harm of aspirin therapy in primary prevention as a function of the 10-year risk of MACE, we favor a nuanced approach still, however, based on the evaluation of cardiovascular risk, acknowledging differences between patients and emphasizing an individualized assessment of both benefits and harm. After optimal control of cardiovascular risk factors, and when patients are less than 70 years of age, clinicians should assess the risk of MACE and base decision on such stratification, considering the risk of bleeding and patient preferences. Clinicians would then advise the use of aspirin in primary prevention patients at the highest risk of MACE who do not have a prohibitive risk of bleeding, and in the majority of cases after initiation of properly titrated statin therapy.
\end{abstract}

\section{Introduction}

The role of thrombosis in acute cardiovascular conditions and the evidence of aspirin's ability to inhibit platelet aggregation have inspired large multicenter trials to test the cardiovascular benefit of aspirin in both primary and secondary prevention. After six inconclusive secondary prevention trials, ${ }^{1-6}$ a metaanalysis-the first one in the cardiovascular field-pooling data from over 10,000 patients with previous myocardial infarction (MI) provided initial evidence for a benefit, with a risk of reinfarction reduced by $21 \%$ compared with placebo. ${ }^{7,8}$ In 1983, a report from the Veterans Administration Cooperative Study on Aspirin in men with unstable angina showed a similar effect on death or acute MI in the setting of unstable angina, ${ }^{9}$ and soon after a Canadian study confirmed favorable effects in received

July 21, 2019

accepted after revision

October 1, 2019 (c) 2020 Georg Thieme Verlag KG Stuttgart · New York
DOI https://doi.org/ $10.1055 / \mathrm{s}-0039-3400294$. ISSN 0340-6245. 
the same condition. ${ }^{10}$ Afterwards, the definitive Second International Study of Infarct Survival (ISIS-2) study demonstrated the clinical utility of aspirin in the acute MI setting, both alone and as an adjunct to fibrinolysis. ${ }^{11}$ Based on these and other results, included in the Antithrombotic Trialists' Collaboration meta-analysis, ${ }^{12}$ low-dose aspirin (75-150 $\mathrm{mg}$ daily) is now universally accepted and recommended for secondary cardiovascular prevention.

By contrast, the benefit-to-risk ratio associated with aspirin use in primary prevention is highly debated, as no trial has shown a clear prognostic benefit, particularly in the post-statin era. ${ }^{13}$ Indeed, the Aspirin to Reduce Risk of Initial Vascular Events (ARRIVE) trial yielded inconclusive results, because of the inadequate statistical power to detect a moderate treatment effect in subjects at low cardiovascular risk, ${ }^{14}$ while the A Study of Cardiovascular Events iN Diabetes (ASCEND) trial did establish the efficacy of low-dose aspirin in reducing risk of serious vascular events in a contemporary, well-treated population of subjects with diabetes mellitus, ${ }^{15}$ and the Aspirin in Reducing Events in the Elderly (ASPREE) study found that low-dose aspirin is not effective in improving disability-free survival in a population of healthy elderly individuals. ${ }^{16-18}$ The primary prevention setting is, however, a heterogeneous mix of subjects at highly variable cardiovascular risk. Primary prevention studies have either included or excluded patients with evidence of subclinical vascular disease, such as asymptomatic stenoses in various arterial districts or indirect signs of atherosclerotic disease, such as cardiac ischemia on provocative testing or reduced ankle-brachial index (ABI), suggesting the presence of peripheral arterial disease. Two recent metaanalyses have either included or excluded such patients, nonetheless concluding that aspirin does not confer a clear clinical benefit. Such conclusions are based on the consideration that the reduction in thromboembolic events is counterbalanced by an increased risk of bleeding. ${ }^{19,20} \mathrm{Simi-}$ lar conclusions have emerged from a further meta-analysis of studies on diabetic patients. ${ }^{21}$

One possible explanation for these results is the progressive reduction in risk of major adverse cardiovascular events (MACEs) in primary prevention that has accompanied global education programs targeting patients to smoke less, exercise more, and increasingly take lipid-lowering therapies. All of these important public health measures could lower the expected benefit from aspirin, while not similarly affecting the risk of bleeding.

Reflecting this diminution of anticipated benefit, guidelines for the use of aspirin in primary prevention have shifted over time and range from "do not use," as described in the 2016 European Society of Cardiology (ESC) recommendations, ${ }^{22}$ to "consider for those at high cardiovascular risk who are not at high bleeding risks" as described in the 2019 American College of Cardiology/American Heart Association (ACC/AHA) Clinical Practice Guidelines for Prevention ${ }^{23}$ ( - Table 1 ). The authors here favor the more nuanced approach of the ACC/AHA, which acknowledges differences between patients and emphasizes an individualized assessment of both benefits and risks. For example, the latter North American guidelines suggest that low-dose aspirin might be considered in primary prevention

Table 1 Recommendations from main recent guidelines on cardiovascular prevention

\begin{tabular}{|c|c|c|c|c|}
\hline Guideline, year [ref.] & Recommendation & Class & LOE & Grade \\
\hline $\begin{array}{l}\text { American College } \\
\text { of Chest Physicians CVD } \\
\text { prevention, } 2012^{40}\end{array}$ & $\begin{array}{l}\text { Low-dose aspirin }(75-100 \mathrm{mg} / \mathrm{d}) \text { in patients aged }>50 \text { years } \\
\text { [is recommended] over no aspirin therapy }\end{array}$ & & & $2 \mathrm{~B}$ \\
\hline $\begin{array}{l}\text { ESC Primary CVD } \\
\text { prevention, } 2016^{22}\end{array}$ & $\begin{array}{l}\text { Antiplatelet therapy (e.g., with aspirin) is not recommended for people } \\
\text { with DM who do not have CVD }\end{array}$ & III & A & \\
\hline $\begin{array}{l}\text { ESC Primary CVD } \\
\text { prevention, } 2016^{22}\end{array}$ & $\begin{array}{l}\text { Antiplatelet therapy is not recommended in individuals without CVD due to } \\
\text { the increased risk of major bleeding }\end{array}$ & III & B & \\
\hline $\begin{array}{l}\text { ACC/AHA Primary } \\
\text { CVD prevention, } 2019^{23}\end{array}$ & $\begin{array}{l}\text { Low-dose aspirin ( } 75-100 \mathrm{mg} \text { orally daily) might be considered for the } \\
\text { primary prevention of ASCVD among select adults } 40 \text { to } 70 \text { years of age } \\
\text { who are at higher ASCVD risk but not at increased bleeding risk }\end{array}$ & IIb & $A$ & \\
\hline $\begin{array}{l}\text { ACC/AHA Primary } \\
\text { CVD prevention, } 2019^{23}\end{array}$ & $\begin{array}{l}\text { Low-dose aspirin (75-100 mg orally daily) should not be administered on a } \\
\text { routine basis for the primary prevention of ASCVD among adults }>70 \text { years } \\
\text { of age }\end{array}$ & III & B & \\
\hline $\begin{array}{l}\text { ACC/AHA Primary } \\
\text { CVD prevention, } 2019^{23}\end{array}$ & $\begin{array}{l}\text { Low-dose aspirin ( } 75-100 \mathrm{mg} \text { orally daily) should not be administered for } \\
\text { the primary prevention of ASCVD among adults of any age who are at } \\
\text { increased risk of bleeding }\end{array}$ & III & $\mathrm{C}$ & \\
\hline $\begin{array}{l}\text { ESC Guidelines on } \\
\text { diabetes, } 2019^{41}\end{array}$ & $\begin{array}{l}\text { In patients with DM at high/very high risk, aspirin }(75-100 \mathrm{mg} / \mathrm{d}) \text { may be } \\
\text { considered in primary prevention in the absence of clear contraindications }\end{array}$ & Ilb & A & \\
\hline $\begin{array}{l}\text { ESC Guidelines on } \\
\text { diabetes, } 2019^{41}\end{array}$ & $\begin{array}{l}\text { In patients with DM at moderate CV risk, aspirin for primary prevention is } \\
\text { not recommended }\end{array}$ & III & B & \\
\hline $\begin{array}{l}\text { ESC Guidelines on } \\
\text { diabetes, } 2019^{41}\end{array}$ & $\begin{array}{l}\text { When low-dose aspirin is used, proton-pump inhibitors should be } \\
\text { considered to prevent gastrointestinal bleeding }\end{array}$ & Ila & A & \\
\hline
\end{tabular}

Abbreviations: ACC/AHA, American College of Cardiology/American Heart Association; ASCVD, atherosclerotic cardiovascular disease; CVD, cardiovascular disease; DM, diabetes mellitus; ESC, European Society of Cardiology; LOE, level of evidence. 
among adults aged 40 to 70 years with higher cardiovascular risk and with no increased bleeding risk, while aspirin should not be prescribed on a routine basis to primary prevention patients aged $>70$ years or among those of any age at increased risk of bleeding (- Table 1).

We here discuss evidence from the three latest trials published in 2018 and provide further rationale for a decisional strategy based on risk stratification. We then propose an algorithm that could be used in clinical practice to assist physicians in deciding whether or not an individual patient should consider use of aspirin in primary prevention.

\section{The ARRIVE, ASCEND, and ASPREE Trials}

\section{ARRIVE: Aspirin for Nondiabetic Patients}

The ARRIVE trial ${ }^{14}$ was a randomized, double-blind, placebocontrolled, multicenter study enrolling men $\geq 55$ years and women $\geq 60$ years with a predicted moderate cardiovascular risk (10-year risk of MACE 10-20\%). Patients at high risk of bleeding were excluded, as well as those with diabetes. Patients ( $n=12,546)$ were randomized in a $1: 1$ ratio to aspirin $100 \mathrm{mg}$ daily or placebo. Over a median of 60 -month followup, there was no significant difference in the occurrence of the primary endpoint (a composite of time to first MI, stroke, cardiovascular death, unstable angina, or transient ischemic attack): hazard ratio (HR) 0.96, 95\% confidence interval (CI) 0.81 to 1.13 ( $p=0.604)$. Similarly, the incidence rates of both fatal and nonfatal MI were not significantly different. With respect to safety, gastrointestinal (GI) bleeding events were more frequent in the aspirin than in the placebo groups (HR $2.11,95 \%$ CI $1.36-3.28 ; p<0.001$ ), although these events were predominantly mild. The incidence of serious adverse events was similar in both treatment groups $(20.19 \%$ in the aspirin group vs. $20.89 \%$ in the placebo group). ${ }^{14}$

Although designed to represent an "intermediate risk" population, the observed incidence rates for MACE in ARRIVE were significantly lower (4\%) than anticipated. As such, we believe the negative benefit-to-risk ratio observed in ARRIVE is informative for contemporary "low-risk" patients, but may not be generalized to those at higher risk.

\section{ASCEND: Aspirin for Diabetic Patients}

Patients with diabetes mellitus have a substantially higher risk of a first atherothrombotic event compared with nondiabetic subjects. Yet, clinical trials with aspirin in this setting have proven inconclusive. ${ }^{24}$

The ASCEND trial $^{15}$ enrolled 15,480 patients aged $\geq 40$ years, with any form of diabetes but no symptomatic cardiovascular disease at baseline. These patients were randomized to aspirin $100 \mathrm{mg}$ daily or placebo, as well as to omega-3 fatty acids versus placebo. Mean age was 63 years, $63 \%$ were male, and $94 \%$ had type 2 diabetes, with median disease duration of 7 years. Other cardiovascular risk factors often coexisted, with $62 \%$ of patients affected by hypertension, $75 \%$ being on statins, and a mean body mass index in the obese range. The primary efficacy outcome was a composite of nonfatal MI, nonhemorrhagic stroke, transient ischemic attack, or cardiovascular death, whereas the primary safety outcome was major bleeding.
Over a mean follow-up duration of 7.4 years, the primary efficacy endpoint occurred in a lower percentage of participants in the aspirin group than in the placebo group (rate ratio [RR] 0.88, 95\% CI 0.79-0.97; $p=0.01$ ). Major bleeding events, however, occurred more frequently in the aspirin group (RR $1.29,95 \%$ CI $1.09-1.52 ; p=0.003)$, with most of the excess being GI bleeding and other extracranial bleeding. ${ }^{15}$

There were no patient subgroups in which benefits clearly numerically outweighed risk, including in the highest risk subgroups; however, as in ARRIVE, overall risk was low to moderate, with only $17.2 \%$ of patients having a 5 -year risk exceeding $10 \%{ }^{15}$

\section{ASPREE: Aspirin for Elderly Fit Individuals}

The ASPREE trial ${ }^{16-18}$ was a randomized, placebo-controlled trial performed in Australia and the United States to investigate whether giving aspirin to healthy, community-dwelling older adults would prolong life free from dementia and physical disability. The trial included subjects aged $\geq 70$ years (or $\geq 65$ years among blacks and Hispanics from the United States), free from life-limiting illness, and with no documented vascular disease. A high bleeding risk was an exclusion criterion. Following a run-in phase to exclude patients with unsatisfactory compliance to treatment, 19,114 subjects were enrolled and randomized in a 1:1 ratio to aspirin or placebo. The median age was 74 years, $56 \%$ were women, $11 \%$ had diabetes, and another $11 \%$ had been on aspirin before. The trial was terminated after a median of 4.7-year follow-up, providing no evidence of benefit from aspirin with regard to the primary endpoint, which was a composite of death, onset of dementia, and persistent physical disability (HR 1.01, 95\% CI 0.92-1.11; $p=0.79$ ). There was a trend toward increased mortality among patients on aspirin (HR 1.14, 95\% CI 1.01-1.29), largely because of a higher incidence of cancer-related death, not achieving statistical significance when accounting for the multiplicity of secondary endpoints analyzed. This finding for cancer is inconsistent with prior reports. With regard to cardiovascular disease, findings from ASPREE were neutral for incident events (HR 0.95, 95\% CI 0.83-1.08) with a consistent increase in major hemorrhage (HR 1.38, 95\% CI 1.18-1.62; $p<0.001$ ). These data thus affirm that aspirin does not confer a net benefit among healthy elderly patients. ${ }^{16-18}$

\section{Toward an Approach Based on Risk Stratification}

The results from the three latest trials, summarized in -Table 2, have been pooled together with previous studies. After the observation that no individual trial has ever shown a mortality benefit from aspirin, ${ }^{13}$ a meta-analysis limited to those unlikely to have underlying atherosclerosis found that aspirin does not reduce all-cause or cardiovascular mortality, but only the risk of MI, while increasing the risk of bleeding. ${ }^{20}$ Another recent meta-analysis used a broader definition of primary prevention ("participants without known preexisting cardiovascular disease"), ${ }^{21}$ and thus included trials with asymptomatic atherosclerotic disease, such as the Prevention of Progression of Arterial Disease and Diabetes (POPADAD) $)^{25}$ 
Table 2 Aspirin for primary cardiovascular prevention: evidence from the latest trials

\begin{tabular}{|c|c|c|c|c|c|}
\hline $\begin{array}{l}\text { Study } \\
\text { (ref.) }\end{array}$ & Study design & Inclusion criteria & $\begin{array}{l}\text { Patient } n \text {, } \\
\text { median FU }\end{array}$ & $\begin{array}{l}\text { Aspirin vs. } \\
\text { placebo: efficacy }\end{array}$ & $\begin{array}{l}\text { Aspirin vs. } \\
\text { placebo: safety }\end{array}$ \\
\hline ARRIVE $^{14}$ & $\begin{array}{l}\text { Randomized, } \\
\text { double-blind, } \\
\text { placebo-controlled, } \\
\text { multicenter study } \\
\text { (Germany, Italy, } \\
\text { Ireland, Poland, } \\
\text { Spain, U.K., U.S.) }\end{array}$ & $\begin{array}{l}\text { Patients } \geq 55 \text { years } \\
(\mathrm{M}) \text { or } 60 \text { years }(\mathrm{W}) \text {, } \\
\text { estimated } \\
\text { moderate CV risk }\end{array}$ & $\begin{array}{l}12,546 \text { patients, } \\
5 \text { years }\end{array}$ & $\begin{array}{l}\text { No significant } \\
\text { differences in: } \\
\text { composite of time } \\
\text { to first MI, stroke, } \\
\text { cardiovascular } \\
\text { death, unstable } \\
\text { angina, or transient } \\
\text { ischemic attack: } \\
\text { HR } 0.96,95 \% \mathrm{Cl} \\
0.81-1.13 \text {, } \\
p=0.604 \text {; fatal or } \\
\text { nonfatal } \mathrm{Ml} \text { : HR } \\
0.85,95 \% \mathrm{Cl} \\
0.64-1.11 \text {, } \\
p=0.233\end{array}$ & $\begin{array}{l}\text { GI bleeding (usually } \\
\text { mild) more } \\
\text { frequent in the } \\
\text { aspirin group } \\
\text { (HR } 2.11,95 \% \mathrm{Cl} \\
1.36-3.28 \text {; } \\
p<0.001 \text { ); similar } \\
\text { incidence of serious } \\
\text { adverse events in } \\
\text { both arms }\end{array}$ \\
\hline ASCEND $^{15}$ & $\begin{array}{l}\text { Randomized, } \\
\text { double-blind, } \\
\text { placebo-controlled, } \\
\text { multicenter study } \\
\text { (U.K.) }\end{array}$ & $\begin{array}{l}\text { Patients } \geq 40 \text { years } \\
\text { diagnosed with } \\
\text { diabetes mellitus } \\
\text { (any type), no } \\
\text { known CV disease, } \\
\text { no clear indication } \\
\text { for antiplatelet } \\
\text { therapy }\end{array}$ & $\begin{array}{l}15,480 \text { patients, } \\
7.4 \text { years }\end{array}$ & $\begin{array}{l}\text { Serious vascular } \\
\text { events less frequent } \\
\text { in the aspirin group } \\
\text { than in the placebo } \\
\text { group (RR } 0.88, \\
95 \% \mathrm{Cl} 0.79-0.97, \\
p=0.01 \text { ) Similar } \\
\text { incidence of Gl } \\
\text { cancer (RR } 0.99 \text {, } \\
95 \% \mathrm{Cl} 0.80-1.24 \text { ) } \\
\text { or any cancer } \\
\text { (RR } 1.01,95 \% \mathrm{Cl} \\
0.92-1.11 \text { ) }\end{array}$ & $\begin{array}{l}\text { Major bleeding } \\
\text { more frequent in } \\
\text { the aspirin group } \\
\text { (RR } 1.29,95 \% \mathrm{Cl} \\
1.09-1.52 ; \\
p=0.003),++\mathrm{Gl} \\
\text { and other } \\
\text { extracranial } \\
\text { bleeding }\end{array}$ \\
\hline ASPREE $^{16-18}$ & $\begin{array}{l}\text { Randomized, } \\
\text { double-blind, } \\
\text { placebo-controlled, } \\
\text { multicenter study } \\
\text { (Australia, U.S.) }\end{array}$ & $\begin{array}{l}\text { Subjects aged } \\
\geq 70 \text { years } \\
\text { (or } \geq 65 \text { years if } \\
\text { blacks or Hispanics } \\
\text { in the U.S.), no } \\
\text { cardiovascular } \\
\text { disease, dementia, } \\
\text { or physical } \\
\text { disability }\end{array}$ & $\begin{array}{l}19,114 \text { patients, } \\
4.7 \text { years }\end{array}$ & $\begin{array}{l}\text { No significant } \\
\text { differences in: } \\
\text { composite of death, } \\
\text { dementia, or } \\
\text { persistent physical } \\
\text { disability (HR } 1.01 \text {, } \\
95 \% \mathrm{Cl} 0.92-1.11 \text {, } \\
p=0.79 \text { ); CV } \\
\text { disease: HR } 0.95 \text {, } \\
95 \% \mathrm{Cl} 0.83-1.08 \text {. } \\
\text { Higher risk of death } \\
\text { from any cause (but } \\
\text { formal comparison } \\
\text { not possible) }\end{array}$ & $\begin{array}{l}\text { Higher rate of } \\
\text { major hemorrhage } \\
\text { in the aspirin group } \\
\text { (HR 1.38; } 95 \% \mathrm{Cl} \\
1.18-1.62 \\
p<0.001 \text { ) }\end{array}$ \\
\hline
\end{tabular}

Abbreviations: Cl, confidence interval; CV, cardiovascular; FU, follow-up; GI, gastrointestinal; HR, hazard ratio; MI, myocardial infarction; RR, relative risk.

and Aspirin for Asymptomatic Atherosclerosis trials. ${ }^{26}$ While confirming the absence of benefit on all-cause mortality and the increased risk of major bleeding, this meta-analysis concluded for a benefit from aspirin in terms of a composite cardiovascular endpoint, as well as MI and ischemic stroke, leading the authors to conclude that "this information may inform discussions with patients about aspirin for primary prevention of cardiovascular events and bleeding."21

\section{When then, if ever, to Prescribe Aspirin in the Setting of Primary Prevention?}

In 2014, a Consensus Document from the ESC Working Group on Thrombosis proposed a therapeutic algorithm based on risk stratification. ${ }^{27}$ According to this document, aspirin should not be prescribed for primary prevention when the estimated 10 -year risk of MACE is $<10 \%$, while it could be considered when the risk was 10 to $20 \%$, especially when the bleeding risk was not increased. Family history of GI cancer would further support aspirin prescription. Aspirin therapy was more firmly advised when the 10-year risk was $>20 \%{ }^{27}$

This treatment algorithm was developed after plotting the relative benefit or harm from aspirin versus placebo as a function of the 10-year risk of MACE, as calculated in the control group of each trial. This analysis suggested that the benefit of aspirin on thromboembolic events increased progressively in parallel with estimated risk of MACE, while the risk of major bleeding from aspirin was generally stable across patient groups (assuming patients at high risk for bleeding are excluded). Therefore, the reduction in 
thromboembolic events was balanced by an increase in risk of bleeding complications in patients with low risk of MACE, whereas patients with higher risk seemed to derive a net benefit from aspirin. As arbitrary cut-points useful for clinical decisions, the 10 and $20 \%$ values of 10 -year risk of MACE were selected, with an area of uncertainty in patients with a 10 -year risk of 10 to $20 \%$. Additionally, the authors proposed to consider patient's bleeding risk and the possible beneficial effect of aspirin toward the development of GI cancer, particularly colorectal cancer, since epidemiologic evidence indicates that regular and long-term use of aspirin is associated with a lower incidence of colorectal and other types of cancer. ${ }^{28}$

The same trends of risk of MACE and bleeding events as a function of 10-year MACE risk are observed in an updated meta-regression including the three latest trials, which either fell below the $10 \%$ threshold (6.8 and $8.3 \%$ in the ARRIVE and ASPREE trials, respectively), ${ }^{14,16-18}$ or just above the same threshold $(10.2 \% \text { in the ASCEND trial })^{15}$-see - Fig. $\mathbf{1 A}$ and -Supplementary Table $\mathbf{S 1}$ (available in the online version). The new trials diminish-but do not eliminate-the significance of the relationship of MACEs versus baseline cardiovascular risk, and the separation of the regression lines depicting the benefit (reduction in MACE) and the risk (increased bleeding) as a function of cardiovascular risk. It should be acknowledged that the trend of MACE risk is driven by the Early Treatment Diabetic Retinopathy Study (ETDRS), ${ }^{29}$ which included patients either in primary or secondary prevention, and statistical significance is lost when this trial is excluded (-Fig. 1B). It should further be noted that the net benefit from aspirin appears different in the only two trials above the $20 \%$ risk threshold, that is, the ETDRS ${ }^{29}$ and POPADAD trials. ${ }^{25}$ Last, clinicians must recognize that trials have been heterogeneous in many aspects over time, including the much more intensive control of cardiovascular risk factors and use of statins in the most recent trials. Despite these issues, the presentation of data in - Fig. 1 continues to suggest that there may be a net benefit from aspirin among those at the very highest levels of risk in primary prevention, as is clearly proven in secondary prevention, provided that conditions of high bleeding risk are excluded.

A potential consequent decision algorithm addressing the use of aspirin in primary prevention is presented in -Fig. $\mathbf{2}$, and this is broadly similar to that recently endorsed by the ACC and AHA..$^{23}$ Importantly, this algorithm only considers prophylactic aspirin among those who are less than 70 years of age for whom optimal control of other risk factors, in particular cholesterol and blood pressure, has already been achieved.

The use of risk thresholds preferably requires the use of American-based score systems (preferably the Atherosclerotic Cardiovascular Disease Score, which estimates the 10-year risk of heart disease or stroke $)^{30}$ even in the European setting, since the European Systematic COronary Risk Evaluation risk charts yield only the risk of fatal atherosclerotic cardiovascular events; the use of this last algorithm would require somewhat imprecise conversion factors to estimate the incidence of MACE. ${ }^{22}$ Additionally, it is important to note that current risk scores seem to overestimate the risk of MACE in contem-
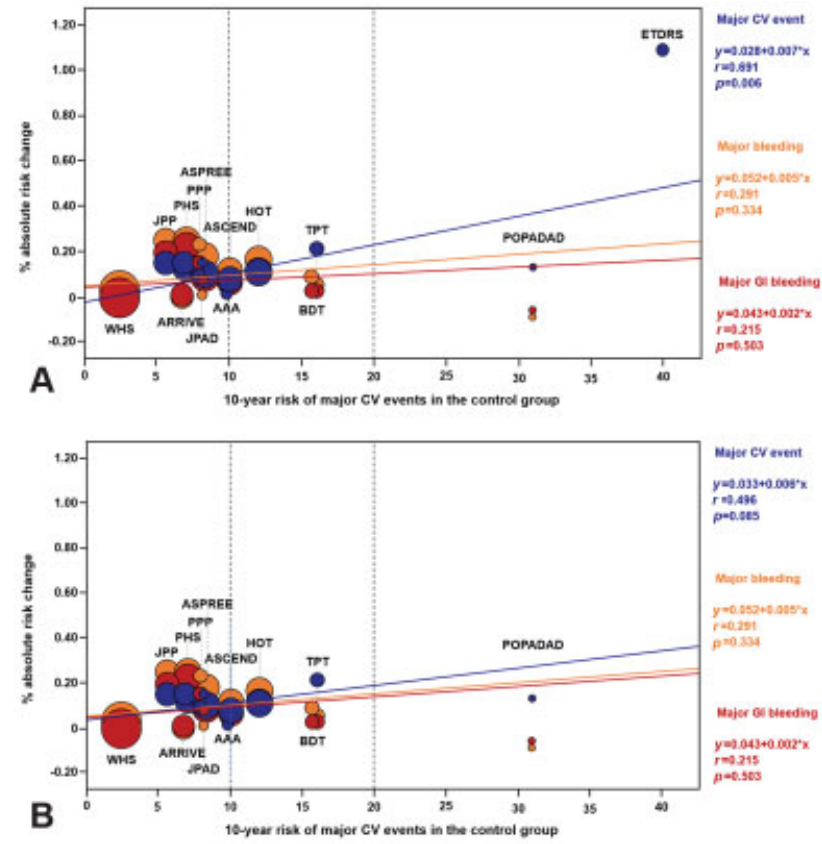

Fig. 1 Relationships between magnitude of antithrombotic benefit and bleeding risk and cardiovascular risk in trials of aspirin for primary prevention. (A) This univariate linear regression reports the aspirin effect as a function of the baseline cardiovascular (CV) risk. The regression lines correspond to major CV events (vascular death, nonfatal myocardial infarction, nonfatal stroke, excluding transient ischemic attacks or need for revascularization), major bleeding, and major gastrointestinal (Gl) bleeding. The independent variable is the risk of major CV events per 10 patient-years in the control group of each trial. On the $y$-axis, the percent absolute risk change is provided; for major CV events, this is calculated as risk/follow-up years in the control group minus risk/years in the aspirin group, while for major bleeding and major GI bleeding, it is calculated as risk/follow-up years in the aspirin group minus the risk/years in the control group. Study weight is proportional to patient number. Each study is represented by three circles (one for each endpoint) whose size is proportional to patient number. Only one and two circles are reported for the Early Treatment Diabetic Retinopathy Study (ETDRS) ${ }^{29}$ and the U.S. Physicians Health Study (PHS), ${ }^{42}$ respectively, since the data reported in the studies do not allow a complete evaluation of the bleeding risk. The ETDRS study is either included (A) or excluded (B) also because the study stands out as a potential outlier. AAA, Aspirin for Asymptomatic Atherosclerosis ${ }^{26}$; ARRIVE, Aspirin to Reduce Risk of Initial Vascular Events ${ }^{14}$; ASCEND, A Study of Cardiovascular Events iN Diabetes ${ }^{15}$; ASPREE, Aspirin in Reducing Events in the Elderly ${ }^{16-18}$; BDT, British Doctors Trial ${ }^{43}$; HOT, Hypertension Optimal Treatment ${ }^{44}$; JPAD, Japanese Primary Prevention of Atherosclerosis With Aspirin for Diabetes ${ }^{45}$; JPPP, Japanese Primary Prevention Project ${ }^{46}$; PHS, Physician Health Study ${ }^{42}$; POPADAD, Prevention of Progression of Arterial Disease and Diabetes ${ }^{25}$; PPP, Primary Prevention Project ${ }^{47}$; TPT, Thrombosis Prevention Trial ${ }^{48}$; WHS, Women's Health Study. ${ }^{49}$ (B) As above, but excluding the ETDRS Study, as this included also patients in what should now be classified as secondary prevention.

porary patient cohorts. ${ }^{31}$ For these reasons, the 10 and 20\% values should be considered as reference points more than fixed thresholds. For patients aged less than 70 years, the $20 \%$ threshold in primary prevention would appear particularly justified, as it is the level of risk observed in current practice in secondary prevention, as in the COMPASS trial, where aspirin is the accepted standard of care..$^{32}$ This level of risk is about half of the risk that patients with stable angina had 
Patients with no previous CV events

and not symptomatic for CV disease

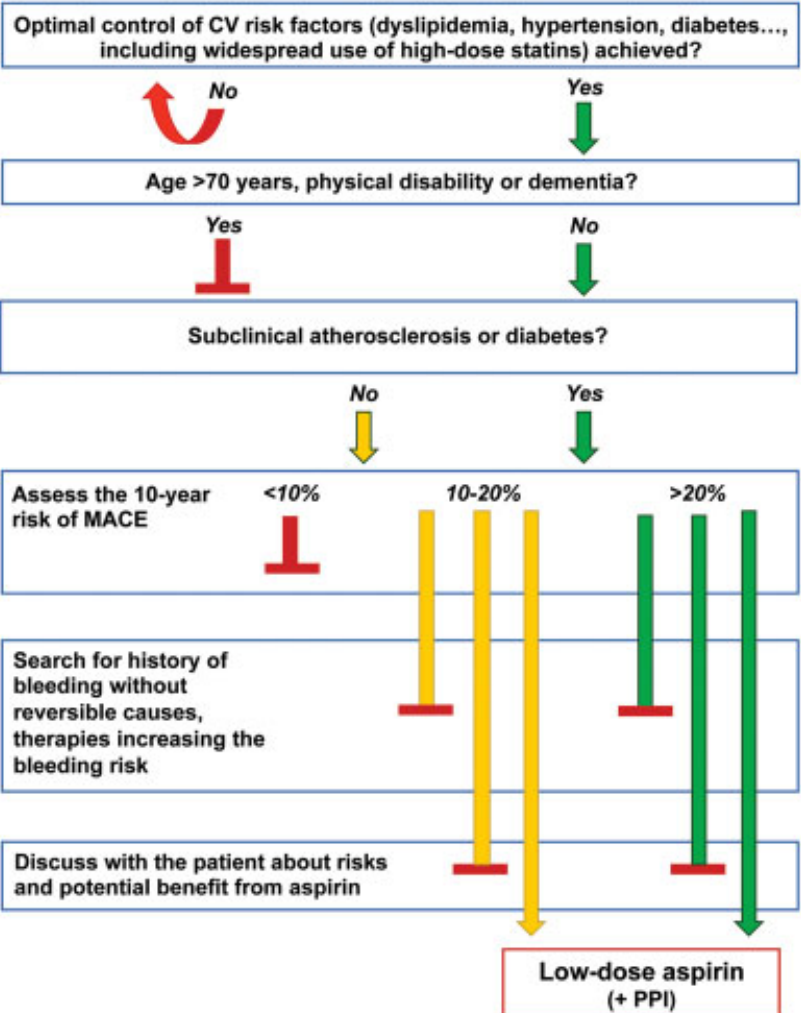

Fig. 2 Proposed stepwise approach to aspirin prescription for primary cardiovascular prevention. Patients in primary cardiovascular (CV) prevention should achieve optimal control of CV risk factors. Afterwards, when they are aged $<70$ years and free from physical disability or dementia, they should undergo a stratification of their CV risk, especially when there is evidence of subclinical atherosclerosis or diabetes. When the 10-year risk of major adverse cardiovascular events (MACE) is $>20 \%$, there is a rationale for starting a therapy with aspirin, particularly if there are no conditions of increased bleeding risk and following discussion with the patient about the potential risks and benefit of aspirin therapy. Aspirin should be prescribed together with a proton-pump inhibitor (PPI) to reduce the risk of gastrointestinal bleeding. Starting of aspirin therapy should be carefully evaluated when the 10 -year risk is between 10 and $20 \%$, and aspirin should not be prescribed when the 10 -year risk is $<10 \%$.

almost three decades ago. ${ }^{33}$ This is also the approximate level of risk attributable to primary prevention with evidence of significant atherosclerosis, such as an $\mathrm{ABI}$ of $<0.9$, , $^{33}$ or evidence of carotid artery plaques or coronary plaques by imaging techniques, ${ }^{34}$ now also available noninvasively, or with moderate/high levels of calcium score ( $>100$ Agatston units). ${ }^{35,36}$ Finally, all patients must be thoroughly informed about the risks and potential benefits from therapy.

It should be noted that no reliable predictors of bleeding exist, and data suggest that cardiovascular risk factors are also risk factors for bleeding. ${ }^{12}$ This would reduce the proportion of individuals that would derive a benefit from aspirin by prevention of cardiovascular events. On the other hand, the proposed approach derives from three considerations:

(1) Although we recognize that risk factors for bleeding largely overlap with cardiovascular risk factors, still the slope of the relationship between the burden of risk factors and MACE appears somewhat steeper than the relationship between the same burden and major bleeding events. The purpose of $\mathbf{- F i g . ~} \mathbf{1}$ is indeed to provide some evidence to this point.

(2) Extracranial bleeding events, particularly in the case of GI bleeding, are usually less serious than MIs or ischemic strokes, and a proper net clinical benefit analysis attributing prognostic weights to nonfatal events, can only amplify the difference between benefit and risk. Clinical judgment on the relative risks of cardiovascular events and GI bleeding may be supported by the use of a dedicated risk calculator, as proposed by Lanas et al. ${ }^{37}$

(3) Additionally, it is important to remind that most GI bleeding events can be prevented through a more widespread use of proton-pump inhibitors, which may be costeffective also in primary cardiovascular prevention. ${ }^{38,39}$

\section{Conclusion}

Given current trial evidence, aspirin remains effective in secondary prevention, but should no longer be recommended for all primary prevention patients, and now probably only for a minority of them. Contemporary trial evidence also indicates that the first pharmacologic step in primary prevention beyond diet, exercise, and smoking cessation should be prescription of a statin, as benefits of this approach are clear and risks exceptionally low and reversible. Nonetheless, with regard to aspirin, we believe a nuanced approach in primary prevention similar to that recently proposed by the $\mathrm{ACC} / \mathrm{AHA}^{23}$ is the best path forward. After optimal control of cardiovascular risk factors, involving in most patients properly titrated statin therapy, and when patients are less than 70 years of age, clinicians should assess cardiovascular risk. When that risk is high and when bleeding risk is not prohibitive, aspirin treatment should be considered, taking into account patients' preferences.

Conflict of Interest

R.D.C. declares having received fees and honoraria from Bayer related to the topic. A.A. and P.M.R. have no conflict of interest to disclose.

\section{References}

1 Elwood PC, Cochrane AL, Burr ML, et al. A randomized controlled trial of acetyl salicylic acid in the secondary prevention of mortality from myocardial infarction. BMJ 1974;1(5905):436-440

2 The Coronary Drug Project Research Group. Aspirin in coronary heart disease. J Chronic Dis 1976;29(10):625-642

3 Breddin K, Loew D, Lechner K, Uberla K, Walter E. Secondary prevention of myocardial infarction: a comparison of acetylsalicylic acid, placebo and phenprocoumon. Haemostasis 1980;9 (06):325-344

4 Elwood PC, Sweetnam PM. Aspirin and secondary mortality after myocardial infarction. Lancet 1979;2(8156-8157):1313-1315

5 The Persantine-aspirin Reinfarction Study (PARIS) Research Group. Persantine and aspirin in coronary heart disease. Circulation 1980; 62:449-461 
6 The Aspirin Myocardial Infarction Study research group. A randomized, controlled trial of aspirin in persons recovered from myocardial infarction. JAMA 1980;243(07):661-669

7 Aspirin after myocardial infarction. Lancet 1980;1(8179):1172-1173

8 Montinari MR, Minelli S, De Caterina R. The first 3500 years of aspirin history from its roots - a concise summary. Vascul Pharmacol 2019;113:1-8

9 Lewis HD Jr, Davis JW, Archibald DG, et al. Protective effects of aspirin against acute myocardial infarction and death in men with unstable angina. Results of a Veterans Administration Cooperative Study. N Engl J Med 1983;309(07):396-403

10 Cairns JA, Gent M, Singer J, et al. Aspirin, sulfinpyrazone, or both in unstable angina. Results of a Canadian multicenter trial. N Engl J Med 1985;313(22):1369-1375

11 ISIS-2 (Second International Study of Infarct Survival) Collaborative Group. Randomised trial of intravenous streptokinase, oral aspirin, both, or neither among 17,187 cases of suspected acute myocardial infarction: ISIS-2. Lancet 1988;2(8607):349-360

12 Baigent C, Blackwell L, Collins R, et al; Antithrombotic Trialists' (ATT) Collaboration. Aspirin in the primary and secondary prevention of vascular disease: collaborative meta-analysis of individual participant data from randomised trials. Lancet 2009;373(9678):1849-1860

13 Ridker PM. Should aspirin be used for primary prevention in the post-statin era? N Engl J Med 2018;379(16):1572-1574

14 Gaziano JM, Brotons C, Coppolecchia R, et al; ARRIVE Executive Committee. Use of aspirin to reduce risk of initial vascular events in patients at moderate risk of cardiovascular disease (ARRIVE): a randomised, double-blind, placebo-controlled trial. Lancet 2018; 392(10152):1036-1046

15 Bowman L, Mafham M, Wallendszus K, et al; ASCEND Study Collaborative Group. Effects of aspirin for primary prevention in persons with diabetes mellitus. N Engl J Med 2018;379(16): 1529-1539

16 McNeil JJ, Nelson MR, Woods RL, et al; ASPREE Investigator Group. Effect of aspirin on all-cause mortality in the healthy elderly. $\mathrm{N}$ Engl J Med 2018;379(16):1519-1528

17 McNeil JJ, Wolfe R, Woods RL, et al; ASPREE Investigator Group. Effect of aspirin on cardiovascular events and bleeding in the healthy elderly. N Engl J Med 2018;379(16):1509-1518

18 McNeil JJ, Woods RL, Nelson MR, et al; ASPREE Investigator Group. Effect of aspirin on disability-free survival in the healthy elderly. $\mathrm{N}$ Engl J Med 2018;379(16):1499-1508

19 Zheng SL, Roddick AJ. Association of aspirin use for primary prevention with cardiovascular events and bleeding events: a systematic review and meta-analysis. JAMA 2019;321(03):277-287

20 Mahmoud AN, Gad MM, Elgendy AY, Elgendy IY, Bavry AA. Efficacy and safety of aspirin for primary prevention of cardiovascular events: a meta-analysis and trial sequential analysis of randomized controlled trials. Eur Heart J 2019;40(07):607-617

21 Khan SU, Ul Abideen Asad Z, Khan MU, et al. Aspirin for primary prevention of cardiovascular outcomes in diabetes mellitus: an updated systematic review and meta-analysis. Eur J Prev Cardiol 2019:2047487319825510

22 Piepoli MF, Hoes AW, Agewall S, et al; ESC Scientific Document Group. 2016 European Guidelines on cardiovascular disease prevention in clinical practice: the Sixth Joint Task Force of the European Society of Cardiology and Other Societies on Cardiovascular Disease Prevention in Clinical Practice (constituted by representatives of 10 societies and by invited experts): developed with the special contribution of the European Association for Cardiovascular Prevention \& Rehabilitation (EACPR). Eur Heart J 2016;37(29):2315-2381

23 Arnett DK, Blumenthal RS, Albert MA, et al. 2019 ACC/AHA guideline on the primary prevention of cardiovascular disease: executive summary: a report of the American College of Cardiology/American Heart Association Task Force on Clinical Practice Guidelines. J Am Coll Cardiol 2019;74(10):1376-1414
24 Capodanno D, Angiolillo DJ. Aspirin for primary cardiovascular risk prevention and beyond in diabetes mellitus. Circulation 2016;134(20):1579-1594

25 Belch J, MacCuish A, Campbell I, et al; Prevention of Progression of Arterial Disease and Diabetes Study Group; Diabetes Registry Group; Royal College of Physicians Edinburgh. The Prevention of Progression of Arterial Disease and Diabetes (POPADAD) trial: factorial randomised placebo controlled trial of aspirin and antioxidants in patients with diabetes and asymptomatic peripheral arterial disease. BMJ 2008;337:a1840

26 Fowkes FG, Price JF, Stewart MC, et al; Aspirin for Asymptomatic Atherosclerosis Trialists. Aspirin for prevention of cardiovascular events in a general population screened for a low ankle brachial index: a randomized controlled trial. JAMA 2010;303(09): 841-848

27 Halvorsen S, Andreotti F, ten Berg JM, et al. Aspirin therapy in primary cardiovascular disease prevention: a position paper of the European Society of Cardiology working group on thrombosis. J Am Coll Cardiol 2014;64(03):319-327

28 Patrignani P, Patrono C. Aspirin and cancer.J Am Coll Cardiol 2016; 68(09):967-976

29 ETDRS Investigators. Aspirin effects on mortality and morbidity in patients with diabetes mellitus. Early Treatment Diabetic Retinopathy Study report 14. JAMA 1992;268(10):1292-1300

30 D’Agostino RB Sr, Vasan RS, Pencina MJ, et al. General cardiovascular risk profile for use in primary care: the Framingham Heart Study. Circulation 2008;117(06):743-753

31 Ridker PM, Cook NR. Statins: new American guidelines for prevention of cardiovascular disease. Lancet 2013;382 (9907):1762-1765

32 Eikelboom JW, Connolly SJ, Bosch J, et al; COMPASS Investigators. Rivaroxaban with or without aspirin in stable cardiovascular disease. N Engl J Med 2017;377(14):1319-1330

33 Criqui MH, Langer RD, Fronek A, et al. Mortality over a period of 10 years in patients with peripheral arterial disease. $\mathrm{N}$ Engl J Med 1992;326(06):381-386

34 Halliday A, Harrison M, Hayter E, et al; Asymptomatic Carotid Surgery Trial (ACST) Collaborative Group. 10-year stroke prevention after successful carotid endarterectomy for asymptomatic stenosis (ACST-1): a multicentre randomised trial. Lancet 2010; 376(9746):1074-1084

35 Nielsen LH, Bøtker HE, Sørensen HT, et al. Prognostic assessment of stable coronary artery disease as determined by coronary computed tomography angiography: a Danish multicentre cohort study. Eur Heart J 2017;38(06):413-421

36 Detrano R, Guerci AD, Carr JJ, et al. Coronary calcium as a predictor of coronary events in four racial or ethnic groups. N Engl J Med 2008;358(13):1336-1345

37 Lanas A, Polo-Tomás M, Casado-Arroyo R. The aspirin cardiovascular/gastrointestinal risk calculator-a tool to aid clinicians in practice. Aliment Pharmacol Ther 2013;37(07):738-748

38 Scally B, Emberson JR, Spata E, et al. Effects of gastroprotectant drugs for the prevention and treatment of peptic ulcer disease and its complications: a meta-analysis of randomised trials. Lancet Gastroenterol Hepatol 2018;3(04):231-241

39 Moayyedi P, Eikelboom JW, Bosch J, et al; COMPASS Investigators. Safety of proton pump inhibitors based on a large, multi-year, randomized trial of patients receiving rivaroxaban or aspirin. Gastroenterology 2019;157(03):682-691.e2

40 Vandvik PO, Lincoff AM, Gore JM, et al. Primary and secondary prevention of cardiovascular disease: Antithrombotic Therapy and Prevention of Thrombosis, 9th ed.: American College of Chest Physicians Evidence-Based Clinical Practice Guidelines. Chest 2012;141:e637S-e668S

41 Cosentino F, Grant PJ, Aboyans V, et al; ESC Scientific Document Group. 2019 ESC guidelines on diabetes, pre-diabetes, and cardiovascular diseases developed in collaboration with the EASD. Eur Heart J 2019;2019:ehz486 
42 Steering Committee of the Physicians' Health Study Research Group. Final report on the aspirin component of the ongoing Physicians' Health Study. N Engl J Med 1989;321(03):129-135

43 Peto R, Gray R, Collins R, et al. Randomised trial of prophylactic daily aspirin in British male doctors. Br Med J (Clin Res Ed) 1988; 296(6618):313-316

44 Hansson L, Zanchetti A, Carruthers SG, et al; HOT Study Group. Effects of intensive blood-pressure lowering and low-dose aspirin in patients with hypertension: principal results of the Hypertension Optimal Treatment (HOT) randomised trial. Lancet 1998;351 (9118):1755-1762

45 Ogawa H, Nakayama M, Morimoto T, et al; Japanese Primary Prevention of Atherosclerosis With Aspirin for Diabetes (JPAD) Trial Investigators. Low-dose aspirin for primary prevention of atherosclerotic events in patients with type 2 diabetes: a randomized controlled trial. JAMA 2008;300(18):2134-2141
46 Ikeda Y, Shimada K, Teramoto T, et al. Low-dose aspirin for primary prevention of cardiovascular events in Japanese patients 60 years or older with atherosclerotic risk factors: a randomized clinical trial. JAMA 2014;312(23):2510-2520

47 de Gaetano G; Collaborative Group of the Primary Prevention Project. Low-dose aspirin and vitamin $\mathrm{E}$ in people at cardiovascular risk: a randomised trial in general practice. Lancet 2001;357 (9250):89-95

48 The Medical Research Council's General Practice Research Framework. Thrombosis prevention trial: randomised trial of lowintensity oral anticoagulation with warfarin and low-dose aspirin in the primary prevention of ischaemic heart disease in men at increased risk. Lancet 1998;351(9098):233-241

49 Ridker PM, Cook NR, Lee IM, et al. A randomized trial of low-dose aspirin in the primary prevention of cardiovascular disease in women. N Engl J Med 2005;352(13):1293-1304 